\title{
LIST OF REFEREES
}

The editorial committee wishes to thank the referees.

- Enyew Adgo

Department Soil Science, Bahir Dar University, Ethiopia

- Giselle Corradi

Department of European, Public and International Law, Ghent University, Belgium,

- Marijke D'Haese

Department of Agricultural economics, Ghent University, Belgium

- Jean-Marie De Ketele

Secteur des Sciences Humaines, Université Catholique de Louvain, Belgium

- Amar Roopanand Mahadew

Department of Law, University of Mauritius, Mauritius

- Julia Sloth Nielsen

Department Public Law and Jurisprudence, University of the Western Cape, South Africa

- Denis Savard

Faculté des Sciences de l'Education, Université Laval, Canada

- Christophe Van der Beken

Institute of Federalism and Legal Studies, Ethiopian Civil Service University, Ethiopia

- Annelies Verdoolaege

Department of Languages and Cultures, Ghent University, Belgium

A special thanks to Stéphanie Schaubroeck for helping with the layout of the tables and figures. 